Abstract G213 Table 1 Bruise location according to mechanism

\begin{tabular}{|c|c|c|c|c|c|c|c|c|c|c|}
\hline Location & $\begin{array}{l}\text { Fall }<1 m \\
(n=131)\end{array}$ & $\begin{array}{l}\text { Impact } \\
(\mathrm{n}=125)\end{array}$ & $\begin{array}{l}\text { Fall: standing } \\
\text { ht. hitting an } \\
\text { object }(n=61)\end{array}$ & $\begin{array}{l}\text { Fall } 1-2 m \\
(n=19)\end{array}$ & $\begin{array}{l}\text { Fall: standing ht } \\
\text { onto toy }(n=19)\end{array}$ & $\begin{array}{l}\text { Crush injury } \\
(n=12)\end{array}$ & $\begin{array}{l}\text { Sports injury } \\
(n=5)\end{array}$ & $\begin{array}{l}\text { Fall } \\
\text { downstairs } \\
(n=5)\end{array}$ & $\begin{array}{l}\text { MVC } \\
(n=7)\end{array}$ & $\begin{array}{l}\text { Total } \\
(\mathrm{n}=384)\end{array}$ \\
\hline Forehead & 35 & 46 & 25 & 4 & 1 & & & 2 & 1 & $114(29.7 \%)$ \\
\hline Knee/shin & 41 & 28 & 2 & 4 & 7 & 1 & 3 & 1 & 1 & $88(22.9 \%)$ \\
\hline Head & 12 & 14 & 6 & 2 & 2 & 2 & & 1 & & $39(10.2 \%)$ \\
\hline Cheek & 5 & 5 & 6 & & 2 & & & & 1 & $19(5 \%)$ \\
\hline Hand & 4 & 2 & 2 & & & 4 & 1 & & & $13(3.4 \%)$ \\
\hline Eye & 2 & 4 & 6 & & & & & & 1 & $13(3.4 \%)$ \\
\hline Trunk back & 8 & 2 & 2 & & & 1 & & & & $13(3.4 \%)$ \\
\hline Thigh front & 4 & 3 & 2 & 1 & & & & & 2 & $12(3.1 \%)$ \\
\hline Arm lower & 5 & 2 & & 4 & & & & & & $11(2.9 \%)$ \\
\hline Buttocks & 3 & 2 & 1 & & 3 & & 1 & & & $10(2.6 \%)$ \\
\hline Foot & 2 & 6 & & 1 & & 1 & & & & $10(2.6 \%)$ \\
\hline Arm upper & 1 & 4 & & 1 & & 2 & & & 1 & $9(2.3 \%)$ \\
\hline Nose & 4 & 1 & & & & & & 1 & & $6(1.6 \%)$ \\
\hline Chin & & 1 & 4 & 1 & & & & & & $6(1.6 \%)$ \\
\hline Mouth & 3 & 1 & & 1 & 1 & & & & & $6(1.6 \%)$ \\
\hline Elbow & 2 & 1 & 2 & & 1 & & & & & $6(1.6 \%)$ \\
\hline Trunk front & & 1 & 1 & & 2 & 1 & & & & $5(1.3 \%)$ \\
\hline Thigh back & & 1 & 2 & & & & & & & $3(0.9 \%)$ \\
\hline Genitalia & & 1 & & & & & & & & $1(0.3 \%)$ \\
\hline
\end{tabular}

\section{G214 THE BEST WAY TO TEACH DEVELOPMENTAL ASSESSMENT - A SINGLE BLINDED RANDOMISED STUDY COMPARING TEACHING MODELS}

doi:10.1136/archdischild-2013-304107.226

S Feyereislova, D Nathan. Community Paediatrics, Nottingham Childrens Hospital, Nottingham University Hospitals Trust, Nottingham, UK

Aims Developmental assessment is a core paediatric competency but research demonstrates teaching gaps. This single blinded, randomised controlled study compares three teaching approaches to developmental assessment in a large group setting based on student's self perception and objective competency assessment.

Methods Students were randomised into one of the following (1) a didactic lecture followed by self study with online resources (control group) (2)a didactic presentation and small group tutorial (small group) (3) a combined didactic lecture and interactive component using audio-visual equipment (Interactive Developmental Teaching-IDT group). The audiovisual system is widely and cheaply available nationally and utilised one teacher and 2 children, and aimed at 45 students.Competency scores (based on the RCPCH scoring system, and adapted for undergraduates), mean score of self reported confidence and degree of motivation were compared.

Results 114 students participated. A statistically significant difference between the mean assessment scores was demonstrated for the small group (38,0; 95\% CI 36,5-39,6) and IDT group (37,9; 95\% CI $36,5-39,4)$ as compared to the control group $(34,8 ; 95 \%$ CI 33,2-36,4). Students' self reported confidence, acquisition of knowledge and degree of motivation to practise after the teaching was higher in the IDT and small group compared to the didactically taught (control) group. The teaching cost, if measured by trainer's time, was one fifth in the IDT group compared to the small group teaching.

Conclusions The IDT is an effective teaching method in large groups, improves competencies compared to didactic lecturing and is as useful as small group teaching. Adoption of the IDT appears to facilitate learning in this important domain and can be feasibly delivered with falling ratios of teachers to students.

\section{G215 "PHONE A FRIEND": USING SIMULATION TO PRACTISE WORKING TOGETHER IN SAFEGUARDING CHILDREN}

doi:10.1136/archdischild-2013-304107.227

'RM Shute, ${ }^{2} \mathrm{~J}$ Runnacles. 'Postgraduate Medical Education Department, Great Ormond Street Hospital, London, UK; ${ }^{2}$ Transformation Team, Great Ormond Street Hospital, London, UK

Aims Paediatric trainees attending a course to support transition to ST4/registrar role reported high anxiety around fulfilling their Safeguarding responsibilities due to lack of experience. They described a widespread practise whereby safeguarding concerns are escalated immediately to seniors, reducing juniors' clinical exposure.

Simulation offers a safe environment to rehearse communication skills essential in Safeguarding, including inter-professional information sharing. We therefore developed a short scenario, "Phone a friend", for this course with the aims to:

1. Provide a learning environment to practise the leadership and communication skills needed to initiate management of a child where there is a safeguarding concern.

2. Help trainees apply safeguarding knowledge, thereby reinforcing learning and building confidence.

Method Collaboratively, we constructed a challenging yet realistic scenario that highlighted key safeguarding themes. In small groups, trainees first observed their colleague take a history from a mother (actor) whose child had presented to A\&E with a non-accidental injury. Realistic supporting information was given (A\&E triage and clerking notes). Another trainee swopped into the "hot seat" and spoke to the 'on-call paediatric consultant' (faculty consultant) for advice and a third trainee spoke to the 'duty social worker' (facilitator) to escalate their concerns. The calls were made on speakerphone and the trainee in role could call 'time out' to ask for advice from the group. This was followed by a structured debrief with individual teams presenting key learning points to the larger group. Results Course feedback showed that trainees valued highly the chance to "run through what you would actually do or say". They 